\title{
O uso do pronome relativo "que" I: que palavra o pronome retoma?
}

\author{
Jocelyne da Cunha Bocchese ${ }^{1,3}$, Valéria Pinheiro Raymundo ${ }^{1,3}$, Márcia Cristina \\ Moraes $^{2,3}$
}

${ }^{1}$ Faculdade de Letras - Pontifícia Universidade Católica do Rio Grande do Sul (PUCRS) Porto Alegre, RS, Brasil

${ }^{2}$ Faculdade de Informática - Pontifícia Universidade Católica do Rio Grande do Sul (PUCRS) Porto Alegre, RS, Brasil

${ }^{3}$ Pró-Reitoria Acadêmica - Pontifícia Universidade Católica do Rio Grande do Sul (PUCRS) Porto Alegre, RS, Brasil

\begin{abstract}
Resumo. A equipe do Laboratório de Aprendizagem da PUCRS desenvolveu, em 2012, três objetos de aprendizagem sobre o uso do "que", com o objetivo de auxiliar alunos ingressantes a identificar contextos de emprego desse pronome, tendo em vista melhorar sua produção escrita em situações acadêmicas. Neste artigo, apresentamos o primeiro objeto da série: "O uso do pronome relativo que I", programado em Flash, está organizado em três módulos: uma introdução, comum a todos os objetos da série; um estudo orientado, que conduz o usuário a compreender o valor pronominal $e$ relacional do "que"; e um estudo prático, composto por dois tipos de exercícios, com graus de dificuldade crescente, de modo a acionar o processo consciente, indispensável para a aprendizagem.
\end{abstract}

\section{Cenário de Uso}

A análise de redações de vestibular com baixo rendimento revela a pouca familiaridade de alguns candidatos com a organização e a linguagem do texto escrito. Além do desconhecimento das convenções da escrita, os desvios assinalados pela banca de corretores sinalizam a interferência indesejável de características do texto falado nas produções dos vestibulandos. A não distinção entre as duas situações discursivas não só compromete a aceitabilidade e a inteligibilidade dos textos avaliados como gera preocupação com o futuro graduando, considerando que, no meio acadêmico, o domínio da língua padrão para a produção de textos é uma exigência.

Entre as ações implantadas pela PUCRS para amenizar esse problema, destacase o trabalho realizado no Laboratório de Aprendizagem (LAPREN) da Universidade. Espaço criado no final de 2009, o LAPREN destina-se a auxiliar estudantes da PUCRS em diversas áreas, por meio de atendimentos individuais ou em grupos. Neste ambiente, são, também, produzidos objetos de aprendizagem sobre conteúdos específicos, para oferecer, tanto à comunidade acadêmica quanto ao público externo, material pedagógico 
online (Wiley, 2015) dinâmico e interativo, de modo a estimular nos estudantes a vontade de estudar por conta própria.

Neste artigo, apresentamos um dos objetos de Língua Portuguesa que compõem o repositório institucional de objetos da PUCRS. O uso do pronome relativo "que" I foi elaborado a partir de dados de redações de vestibulandos e destina-se tanto a alunos do Ensino Médio quanto a graduandos, visto que o material pode ser utilizado para apresentar e/ou revisar o conteúdo.

Nas 50 redações analisadas, foram identificadas 34 ocorrências de uso inadequado do "que". Segundo Ataliba Castilho (2010), o "que" está ocupando os espaços de outros pronomes relativos, como uma espécie de pronome relativo universal. De acordo com o autor, nota-se que o relativo se despronominaliza, transformando-se numa conjunção com papel exclusivamente relacional, fenômeno que se caracteriza pela provável transferência de estruturas da fala informal para a escrita formal, interferindo negativamente nas produções acadêmicas. A partir dessa constatação, o objeto $O$ uso do pronome relativo "que” I foi desenvolvido.

\section{Desenvolvimento}

A produção e o desenvolvimento de objetos de aprendizagem do LAPREN envolvem uma equipe multidisciplinar, visto que o processo engloba diferentes etapas: elaboração, revisão, programação e evolução (Moraes et al. 2011).

$\mathrm{Na}$ etapa inicial, duas professoras da Faculdade de Letras da PUCRS elaboraram um roteiro em Power Point contendo textos, exercícios e propostas de interações e animações. Finalizada a primeira versão do roteiro, reuniram-se com a equipe de desenvolvimento (programador, professora da área de Comunicação e professora da área de Computação) para explicar o funcionamento do objeto, momento em que foram sugeridas possibilidades de aperfeiçoamento e de implementação do material: interação entre as telas, layout, animações e interações, além de outras questões de usabilidade.

Revisado o roteiro, iniciou-se a fase de desenvolvimento, realizada através de diferentes entregas, em um processo de desenvolvimento ágil (Schwaber, 2004). A cada etapa, algumas funcionalidades eram programadas, testadas e revisadas tanto em aspectos referentes ao conteúdo, quanto a questões de usabilidade e navegabilidade do objeto. O objeto foi desenvolvido em Flash e pode ser acessado de qualquer navegador que possua um plugin para esta ferramenta. Após a finalização da implementação, o objeto foi cadastrado no repositório do LAPREN, que utiliza o sistema DSpace. O DSpace é um software livre desenvolvido pelo MIT e HP e que possibilita o armanezamento, gerenciamento e recuperação de materiais digitais (Smith, 2003). O padrão de metadados utilizado pelo Dspace do LAPREN é o Dublin Core.

Concluída a etapa de programação, deu-se início à fase de evolução, em que o material passou a ser avaliado por bolsistas de Iniciação Científica vinculados ao laboratório, mediante o preenchimento de uma ficha de avaliação, contemplando quatro diferentes aspectos: cadastro, conteúdo, formatação e navegação (Figura 1). 
CBIE-LACLO 2015

Anais dos Workshops do IV Congresso Brasileiro de Informática na Educação (CBIE 2015)

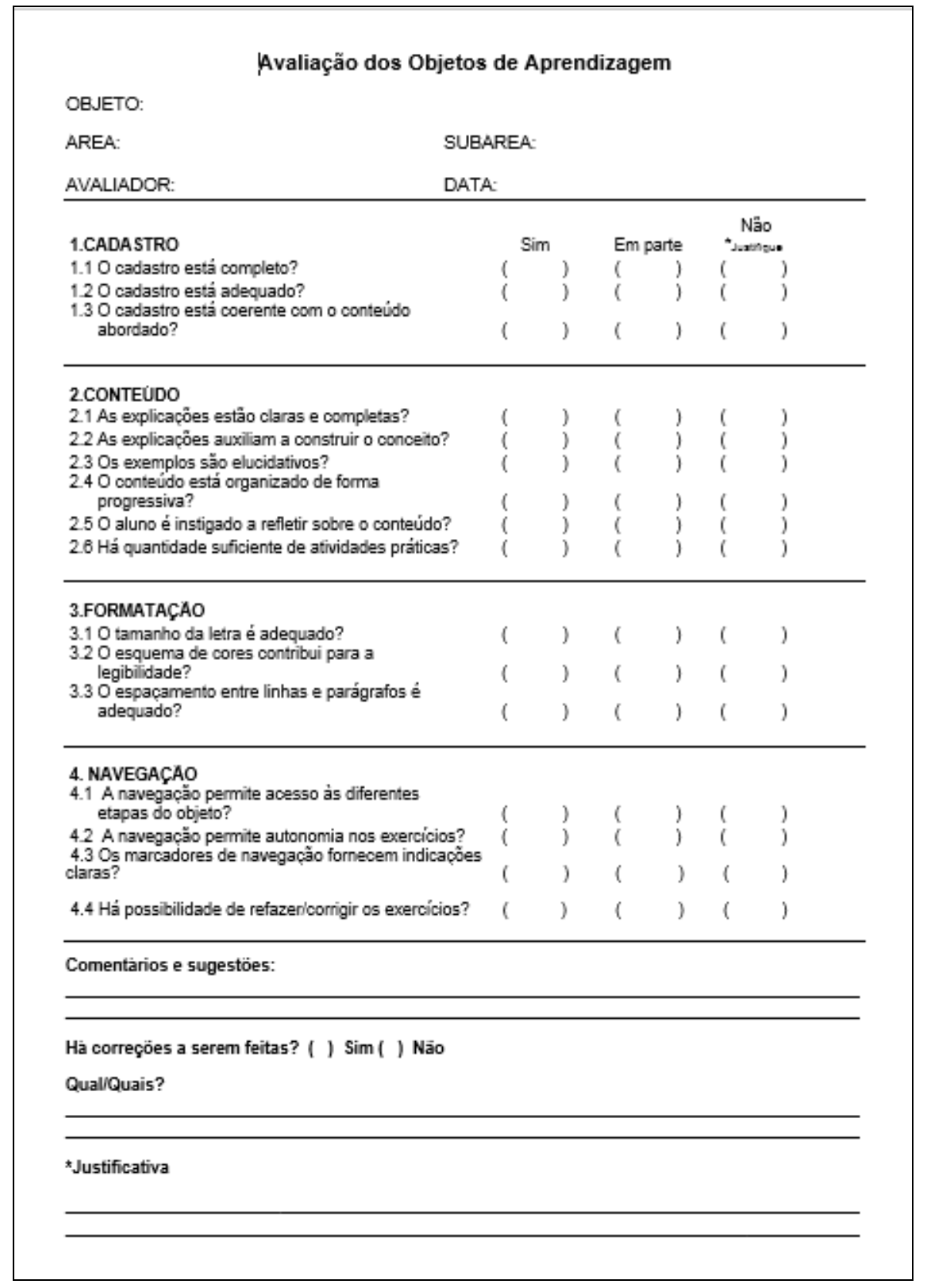

Figura 1. Ficha de Avaliação dos Objetos de Aprendizagem do LAPREN

\section{Apresentação do software}

O objeto $O$ uso do pronome relativo "que" I está disponível no repositório de objetos de aprendizagem da PUCRS, no endereço http://lapren.pucrs.br, e pode ser acessado na Comunidade Objetos de Aprendizagem, Subcomunidade Linguística, Letras e Artes, Coleção de Língua Portuguesa. O material está associado à licença Creative Commons 3.0. O vídeo de apresentação sobre o objeto de aprendizagem está disponível no endereço https://vimeo.com/user25815119/review/130225349/09134dce06.

O uso do pronome relativo "que" I foi organizado em três módulos: o primeiro - introdução - consiste em apresentação do problema a partir de duas situações comunicativas reais: uma informal e outra formal (Figuras 2 e 3); o segundo - estudo orientado - conduz o usuário a compreender o valor pronominal e relacional do "que" 
CBIE-LACLO 2015

Anais dos Workshops do IV Congresso Brasileiro de Informática na Educação (CBIE 2015)

(Figura 4); o terceiro - estudo prático - é composto por dois tipos de exercícios, com graus de dificuldade crescente, que levam o aluno a identificar os antecedentes desse pronome (Figura 5) e a utilizá-lo de forma adequada em uma proposta de produção escrita (Figura 6).

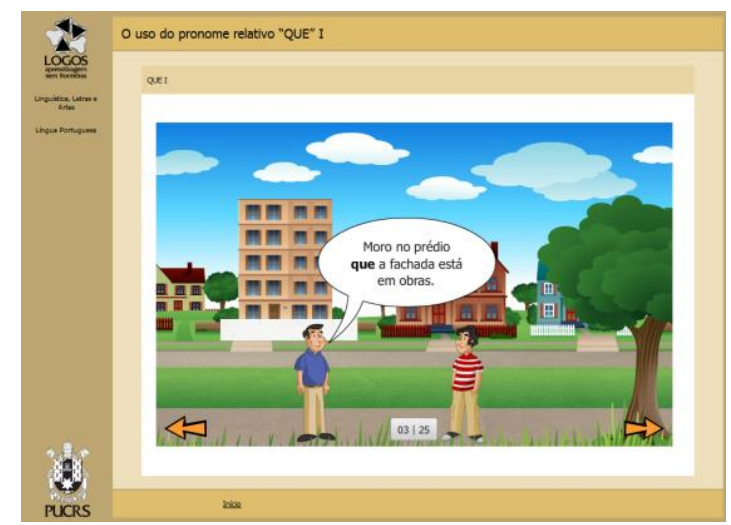

Figura 2. Introdução: apresentação de uma situação comunicativa informal

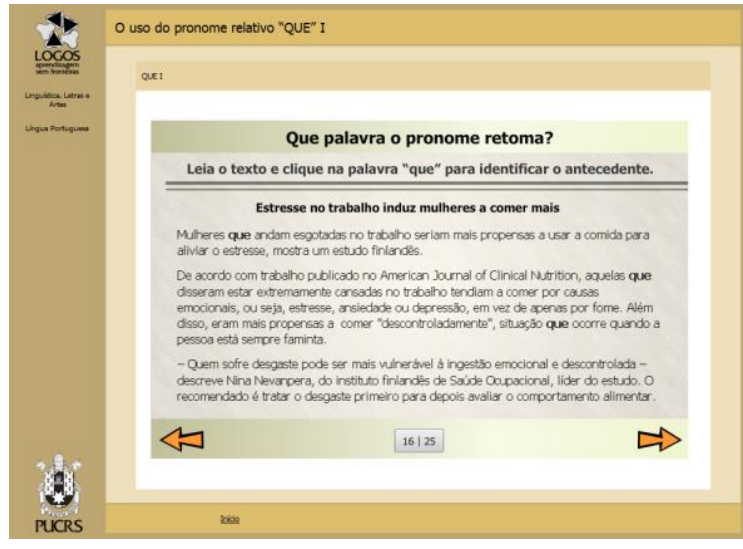

Figura 4. Estudo orientado: o valor pronominal e relacional do "que"

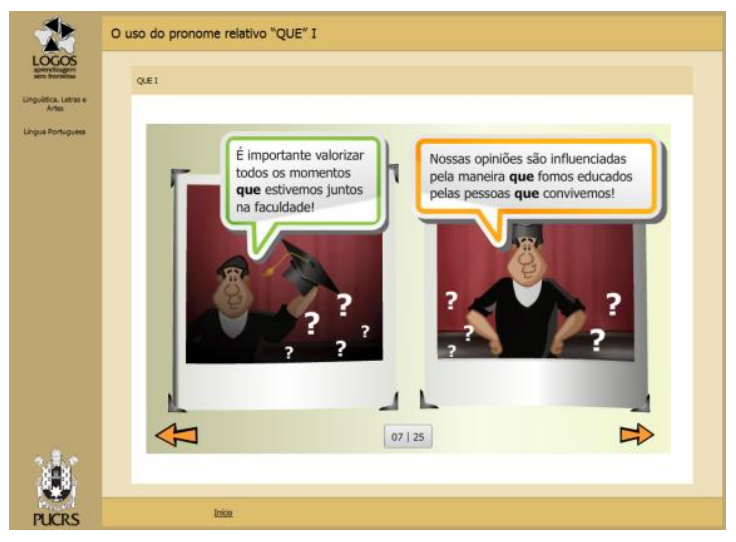

Figura 3. Introdução: apresentação de uma situação comunicativa formal

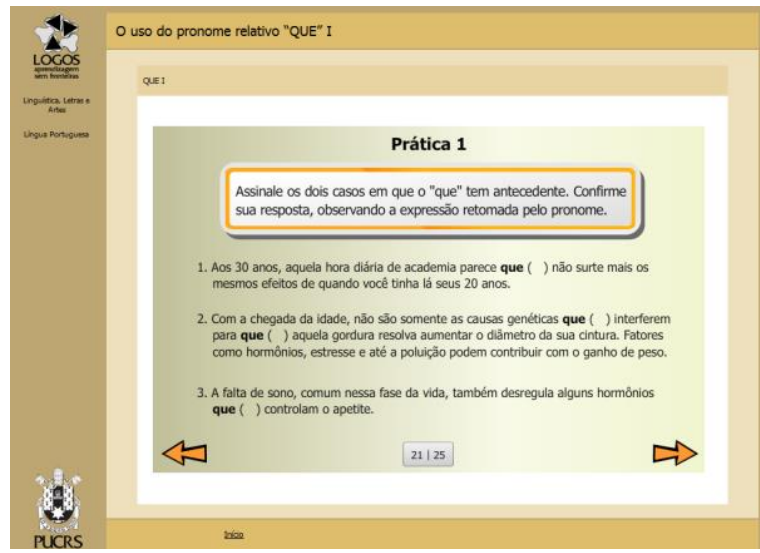

Figura 5. Estudo prático: identificação do antecedente do pronome

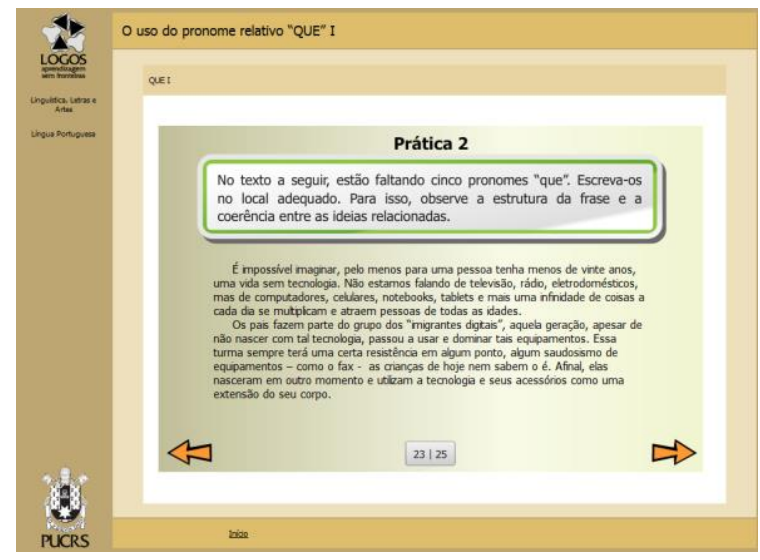

Figura 6. Estudo prático: utilização adequada do pronome relativo "que" 
CBIE-LACLO 2015

Anais dos Workshops do IV Congresso Brasileiro de Informática na Educação (CBIE 2015)

A construção do objeto inspirou-se em uma proposta de ensino gramatical mais produtivo, fundamentado nos princípios da análise linguística, abordagem pedagógica que propõe uma compreensão mais ampla dos usos e do sistema linguístico do que a abordagem puramente gramatical, buscando conduzir a construção dos conceitos de maneira que o aprendiz seja capaz não apenas de identificar o valor pronominal do "que", mas também de refletir sobre os fenômenos gramaticais e textuais que perpassam os usos da língua e os sentidos resultantes das escolhas feitas pelos falantes em uma determinada situação comunicativa (Figura 7), partindo de "uma reflexão explícita e organizada para resultar na construção progressiva de conhecimentos e categorias explicativas dos fenômenos em análise" (Mendonça, 2006). Para isso, oferece acesso às respostas esperadas (Figura 8).

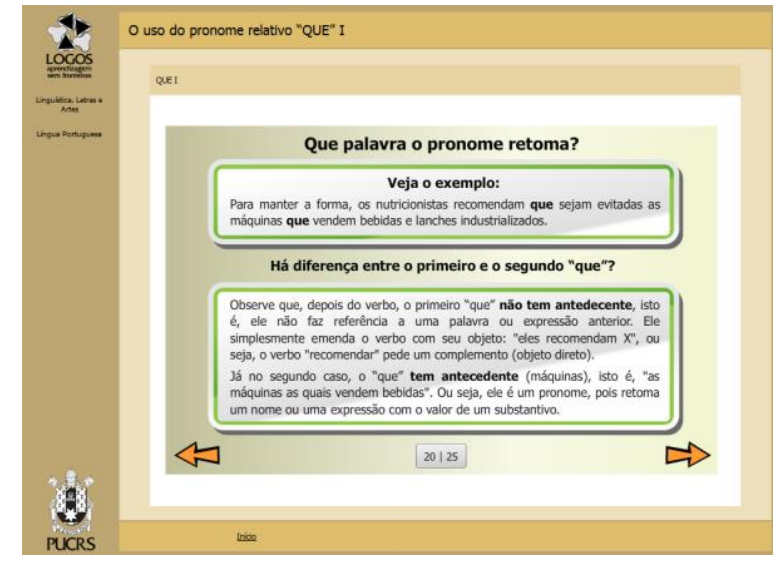

Figura 7. Proposta de reflexão sobre o uso do pronome relativo "que"

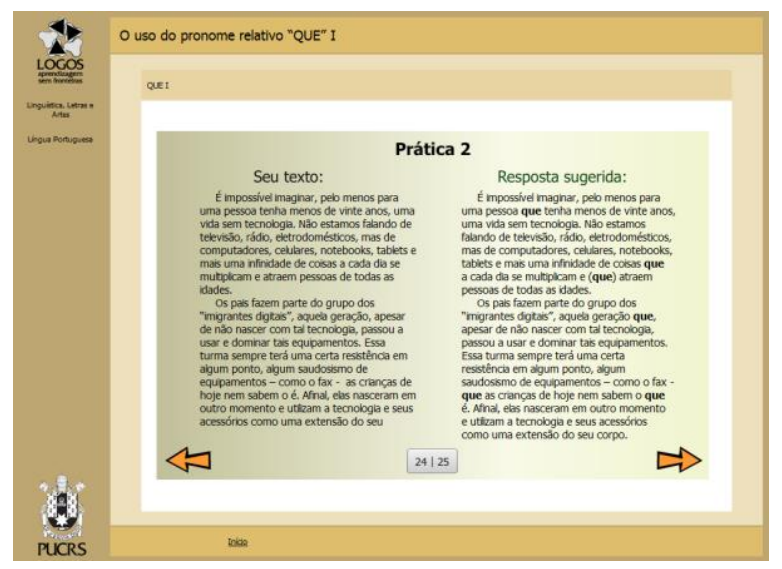

Figura 8. Acesso à resposta sugerida

Como o material foi desenvolvido para acionar o processamento do sistema consciente, o aluno é constantemente instigado a pensar, analisar e refletir sobre os itens linguísticos focalizados, exigindo-se, sempre que possível, a comparação entre as produções aceitáveis na fala e as exigidas na escrita formal (Figura 9). Espera-se que, ao fazê-lo, o aprendiz desenvolva capacidades e habilidades que lhe permitam melhorar seu desempenho linguístico e sua atenção executiva, com reflexos positivos no aproveitamento acadêmico.

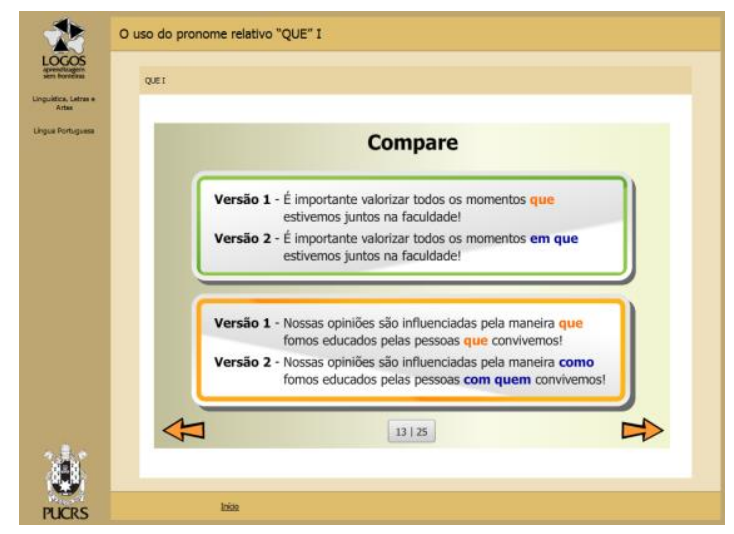

Figura 9. Comparação entre os usos do pronome: fala informal e escrita formal 


\section{CBIE-LACLO 2015}

Anais dos Workshops do IV Congresso Brasileiro de Informática na Educação (CBIE 2015)

O material que ora descrevemos constitui o primeiro objeto de uma série de três que procuram levar o aprendiz a compreender os usos do pronome relativo "que" e de suas variantes em situações formais de escrita na universidade. A sequência didática proposta organiza-se de forma progressiva, iniciando com os conceitos mais simples para depois abordar os mais complexos. Dessa forma, o primeiro objeto enfoca o valor correferencial do pronome relativo, de modo a permitir que o aluno compreenda a importância do "que" como pronome para a coesão do texto. O segundo focaliza o valor relacional do pronome relativo, para que o aprendiz possa perceber que o pronome também funciona como um nexo que une orações. E o terceiro material analisa as diferentes funções do pronome e de suas variantes na oração relativa, envolvendo também questões de regência (Figura 10). Dado que os materiais tratam de três aspectos do mesmo conteúdo, todos partem da mesma introdução, permitindo que o usuário elimine essa etapa (Figura 11), caso já tenha trabalhado com ela, e que transite de um material (Figura 12).

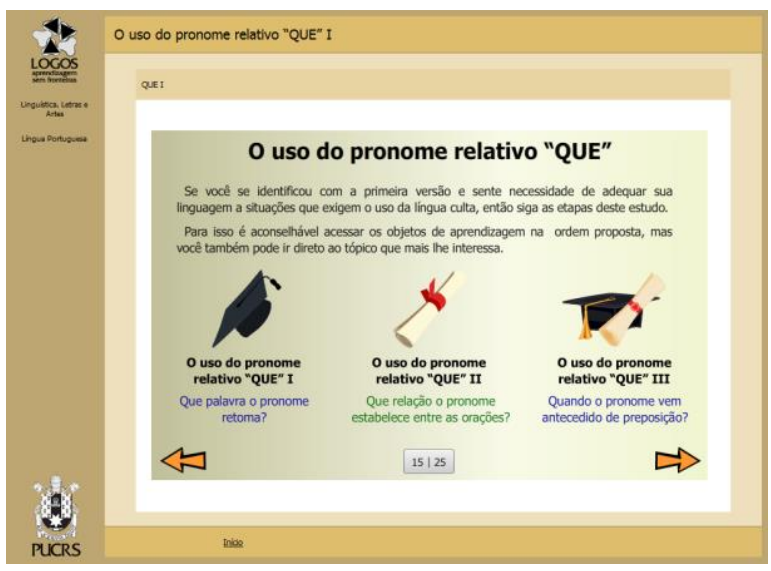

Figura 10. Menu com os três objetos da série

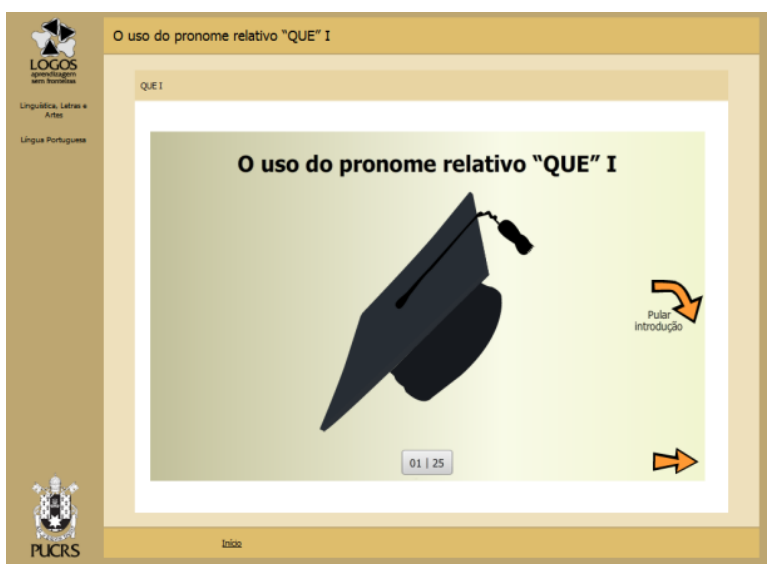

Figura 11. Possibilidade de navegação: pular a introdução

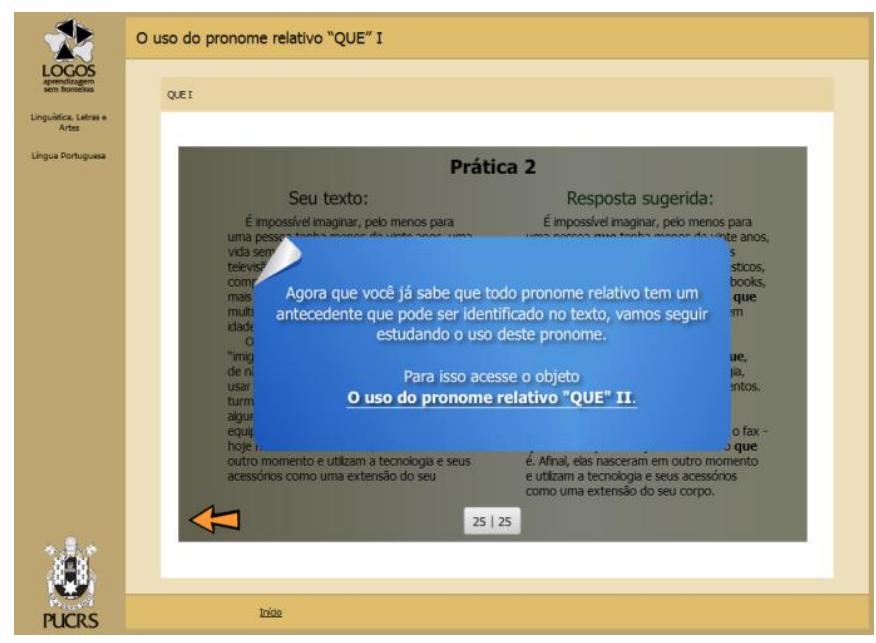

Figura 12. Link que remete a outro objeto da série 
CBIE-LACLO 2015

Anais dos Workshops do IV Congresso Brasileiro de Informática na Educação (CBIE 2015)

\section{Considerações finais}

Disponibilizado em 2012, através do repositório de objetos de aprendizagem da PUCRS (https://lapren.pucrs.br/), o material foi avaliado, até o momento, por quatro bolsistas de iniciação científica da Licenciatura em Letras, vinculados ao LAPREN. Nessas avaliações, o material foi considerado satisfatório em todos os quesitos da ficha mencionada. Também foi acessado e analisado em oficinas destinadas a professores de Língua Portuguesa do Ensino Médio de diferentes escolas do Rio Grande do Sul, que visitaram o laboratório durante a Feira de Profissões da Universidade, em 2014. Nessa ocasião, os professores consideraram adequada a divisão do estudo inicial sobre o emprego do pronome relativo em três OAs mais curtos, com objetivos claros e bem delimitados, estabelecendo-se links entre eles. Assim os usuários - sejam eles professores ou alunos - podem dispor de mais liberdade e autonomia para monitorar as etapas e o tempo de aprendizagem, com a possibilidade de utilizar um ou mais objetos em diferentes momentos, para introduzir ou revisar os conteúdos abordados, adequandoos aos seus cronogramas de aulas.

Atualmente, estamos trabalhando na adaptação do objeto para seu uso em dispositivos móveis. Neste sentido, uma versão em HTML5 está sendo desenvolvida. Para 2016, pretende-se acrescentar mais dois objetos à série: um que aborde os usos dos pronomes "cujo" e "onde" na escrita formal; e outro que possa servir como instrumento de "autoavaliação" do uso das construções com pronomes relativos em exercícios com grau crescente de dificuldade, não só para que o aluno possa monitorar sua aprendizagem, mas também para que professores possam utilizá-lo como instrumento de diagnóstico e de medida da evolução da aprendizagem do estudante, podendo, ainda, constituir instrumento de pré-teste e pós-teste de futuras pesquisas.

\section{Referências}

CASTILHO, Ataliba Teixeira de. Nova gramática do português brasileiro. São Paulo: Contexto, 2010.

DUBLIN CORE. "Dublin Core Metadata Initiative”, http://dublincore.org/, July.

MARCUSCHI, Luiz Antônio. Da fala para a escrita: atividades de retextualização. São Paulo: Cortez, 2001.

MORAES, M. and RAYMUNDO, V. and BOCCHESE, J. and LIMA, V. "Elaboração de Objetos de Aprendizagem para o LAPREN: Processo de Desenvolvimento e Sistema de Produção", http://www.br-ie.org/sbie-wie2011/, June.

SCHWABER, Ken. Agile project management with scrum. Redmond (WA) : Microsoft, 2004. 163 p.

SMITH, M. et al. "Dspace: an open source dynamic digital repository". D-Lib Magazine, 9, 1 (2003), http://www.dlib.org/dlib/january03/smith/01smith.html,July. 
CBIE-LACLO 2015

Anais dos Workshops do IV Congresso Brasileiro de Informática na Educação (CBIE 2015)

WILEY, D. Connecting learning objects to instructional design theory: a definition, a metaphor and a taxonomy. In: The instructional use of learning objects - On-line Version. 2000. Disponível em: http://reusability.org/read/. Acessado em maio de 2015. 